\title{
Application of IoT for the Maintaining Rolling Stocks
}

\author{
DOI: 10.12776/QIP.V21I2.887
}

\author{
Sang Chan Park, Yoo Jung Kim, Jong Un Won
}

Received: 03 March 2017 Accepted: 29 April $2017 \quad$ Published: 31 July 2017

\begin{abstract}
Purpose: This paper presents a framework for simulation on IoT based CBM (condition based monitoring) for rolling stocks. This enables to allocate maintenance resources effectively while satisfying preventive maintenance requirements.
\end{abstract}

Methodology/Approach: We exploits Reliability centered maintenance (RCM) based on KTX (Korea Tran eXpress, Korea's high-speed rail system) motor reduction unit failure data for three years by utilising the internet of things (IoT) and RAMS (Reliability, Availability, Maintainability, Safety) methods.

Findings: We come up with the predictive maintenance indicator; reliability functions as to the desired service level; and the failure and defect prediction indicator takes the form of cumulative failure function in the form of probability distribution function, which aim to realise the real-time condition monitoring and maintaining technical support services. Internet of Things (IoT) has been an important apparatus to improve the maintenance efficiency.

Research Limitation/implication: This paper has limitations that the data are collected from references, not actual data; the detailed descriptions of IoT application to the railway rolling stocks are omitted, and it is not dealt in depth how maintenance efforts and performance are improved through the suggested reliability centered maintenance.

Originality/Value of paper: This study has the academic importance in a sense that it integrates RAMS based maintenance methods and IoT. RAMS centered maintenance provides powerful rules for deciding a failure management policy; when it is technically appropriate; and for providing precise criteria for deciding how often routine tasks should be carried out. It will lead to the improved cost efficiency, sustainability and maintainability of railway maintenance system since the staff do not have to visit installation sites frequently. Lately, there is general agreement that prevention was better than inspection and that an increase 
in preventive cost was the means of reducing total quality costs. In connection with this issue, we will address the way of reducing failure costs and prevention costs with IoT: new appraisal method.

Category: Conceptual paper

Keywords: railway rolling stocks; maintenance; IoT; RAMS; PAF model

\section{INTRODUCTION}

The objective of a railway is to perform a defined railway traffic service safely within a scheduled time and limit budgets. The complexity of railway industry brings the necessity for seeking effective methods for day to day operation and appraising the results in the light of the long-run objectives of the railroad (Charnes and Miller, 1956). Railway RAMS management is an engineering discipline to conduct integrated systems with the policy, objectives, principles, criteria, techniques, method and tools (Park, 2016).

However, there has been a trade-off on the baseline of the RAMS both on day to day operations and long-term maintenance. For example, on day to day operation, availability trade off for safety and cost. If the goal of railway service is improving availability, which is defined in both readiness at the departure station and the arrival time at the terminal station, it will decrease safety as defined in risk assessment.

On long term maintenance, there is trade-off between reliability and availability. When railway organisations set service level to improve reliability, the ability that a system can perform its intended function over a given time without any failure, it will decrease availability performance. Moreover, failure prediction of railway system is more difficult because of complexity of the system and its insufficient data source (Park, 2016).

If we can bring IoT technology into railway industry, it will bring high impact to many aspects of the railway RAMS management. In contrast to trade off of availability, safety and cost aspect, we could see the effect of monotonic, continuous increase of availability and safety. Also, their high availability requires a significant amount of costs, but IoT cut down the cost of infrastructure technologies by distributing to common carriers. Not only that, railway operators are allowed to use efficient monitoring system and dependability RAMS management by adapting their requirements depending on railway service level and operational strategies.

It may be useful to start out by examining the effectiveness of application IoT on the railway. This paper will provide a framework for simulation on IoT based CBM (condition based monitoring) for rolling stocks. The first part discusses the background of railway management technique based on the current system state. The second part presents the research methodology which adopted IoT for longterm maintenance. We discuss the outline of methodology for the RAMS 
management in IoT monitoring system with failure data. The third part provides the result of methodology. This part includes identifying the benefit of IoT implementation.

\section{LITERATURE REVIEW}

\subsection{RAMS}

RAMS (reliability, availability, maintainability and safety, IEC 62778) analysis is an important step in the design and the operation of productions and services (Barabadi, Gudmestad and Barabady, 2015). The aim of railway RAMS is achieving a defined level of rail traffic in a given time with a given safety level.

Reliability characteristic represents the ability that a system can perform its intended function over a given time without any defined failure. Maintainability is a system characteristic that designs the ease of maintenance within the structure of a system. Availability characteristic means the ability to operate a system at the starting point of the required mission whenever required by operator. Finally, safety is a system design characteristic to provide freedom from unacceptable risks with regard to operation, maintenance, person, environment, and equipment.

The RAMS definition can be tailored from the framework of Fig. 1, depending on railway service objectives and operational strategies. For example, the goal of the railway service is to achieve the level of a defined railway traffic service within the defined time and limited cost safely (Park, 2016).

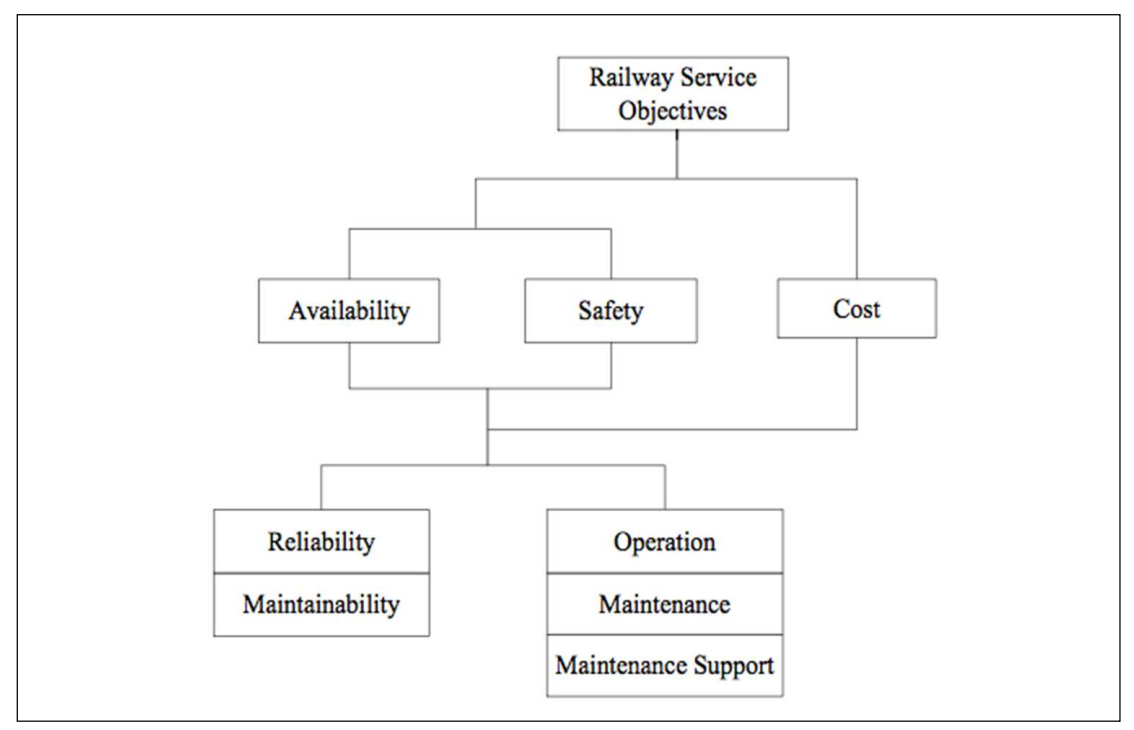

Figure 1 -Definition of Railway RAMS Elements (Park, 2016) 
To improve the quality and the efficiency of railway services, acquiring the system with high RAMS performance and monitoring the operation and maintenance policies are needed (Kim, et al., 2008). Therefore, Korail specifies RAMS requirements in the system specification when it purchases the equipment and rail stocks. Also, RAMS centered maintenance procedure is needed to achieve the inherence RAMS performance of the acquired system continuously.

The importance of reliability centered maintenance (RCM) and its effect in RAMS analysis is highlighted in many literature. For example, Kim, et al. (2008) proposed the conceptual model for determining optimal maintenance interval after evaluating the effect on RAMS centered maintenance system for railway. Hameed, Vatn, and Heggset (2011) emphasized that failure mechanisms, failure models and operational conditions of wind turbines component should be collected in RAMS data based, after reviewing challenges in reliability and maintainability data collection for offshore wind turbines. Duarte, Cunha, and Craveiro (2013) showed that the reliability characteristics of equipment which is evaluated in design phase could partially change during the operational phase with huge effect on performance of production facilities. Hence, they mentioned that all the influence operational conditions should be collected in the maintenance database.

Reliability centered maintenance (RCM) is a process used to decide what must be done to ensure that any physical asset, system or process continues to do whatever its users want it to do. Therefore, RCM provides powerful rules for deciding whether a failure management policy is technically appropriate, providing precise criteria for deciding how often routine tasks should be carried out. RCM identifies ways which the system can fail during their lifespan. This must generally be followed by a failure mode and effects analysis (FMEA) which allows an assessment of the consequences of failure.

FMEA is a systematic analysis of the potential failure modes of a component of a system (Price, et al., 1995). It includes the identification of possible failure modes, determination of the potential cases and consequences and an analysis of the associated risk. It also includes a record of corrective actions or controls implemented resulting in a detailed control plan (Taylor, 1998). The FMEA allows identifying the most critical components and the likely failure mechanisms, thus leading to the specification of system parameters to be monitored. 


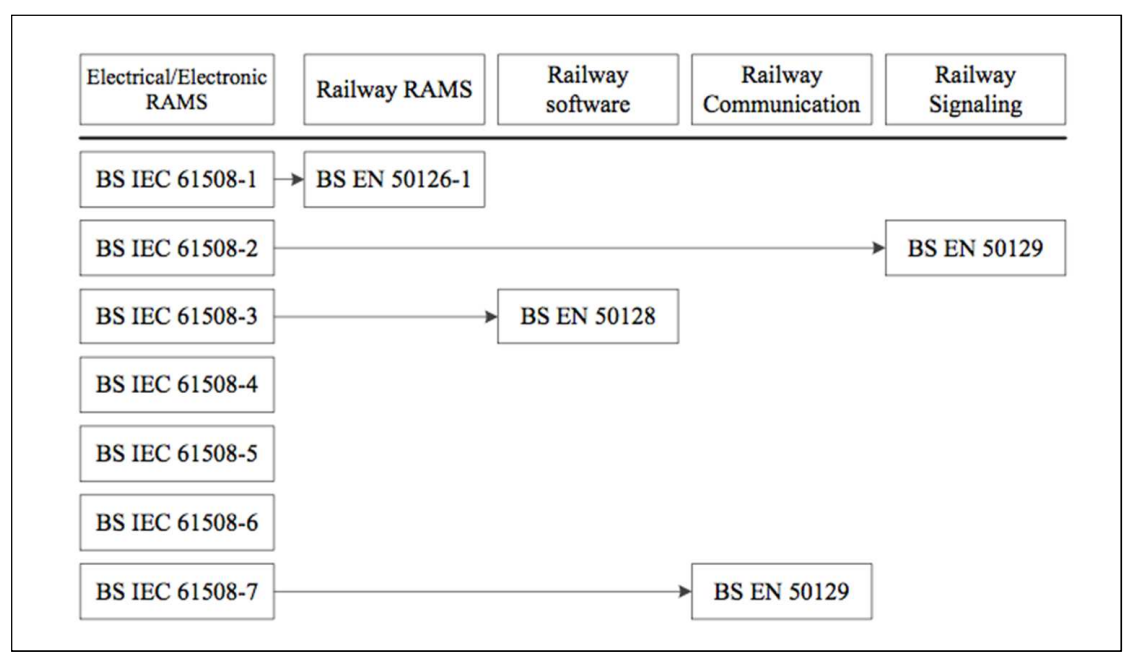

Figure 2 - Railway RAMS Management Standards (Park, 2016)

\subsection{IoT Monitoring System}

In practice, time based monitoring is obtained at discrete monitoring time intervals. This type of time based monitoring is called indirect monitoring in contrast to direct monitoring which measures the actual condition. The latter, condition based monitoring, employs advanced electronics, sensors, and transducers, computing and communication technology.

Internet of Things (IoT) aims to establish interconnection of objects in the physical world and integrates countless electronic devices around us and a large number of technologies into the network. Hence, cooperation with other people to achieve common goals, interaction with each other and provision of information on a real time basis through standard communication protocols and unique addressing schemes can be achieved by IoT. If we can bring IoT technology into the railway condition monitoring system, it will bring high impacts to many aspects of maintenance and greatly increase the maintenance efficiency.

To improve the maintenance efficiency and save the maintenance cost, IoT technology has been introduced into remote handling maintenance process. IoTbased remote handling maintenance process has been designed for remote condition monitoring. Especially it has been applied in a harsh environment such as an arctic region (Barabadi, Gudmestad and Barabady, 2015), and a desert area.

The system dynamically monitors, collects, records and analyzes equipment parameters to perform fault diagnosis and fault prediction; it also carries out the analysis of the changing trends of fault parameters to ascertain the degradation extent and fault location. Thus appropriate maintenance mode, trouble location, and remaining lifespan can be determined based on the system (Scarf, 1997). 


\subsection{Condition Based Monitoring (CBM)}

Condition based maintenance (CBM) aims at achieving reliable and costeffective operation of engineering systems such as aircraft systems, wind turbine generators, hydro power plants and manufacturing systems (Jardine, Lin and Banjevic, 2006). In CBM, condition monitoring data, such as vibration data, oil analysis data, and acoustic data, are collected and processed to determine the equipment health condition (Tian, 2007). Future health condition and the remaining useful life (RUL) of the equipment is predicted.

Thus, optimal maintenance actions are scheduled based on the predicted future equipment health condition, so preventive replacements can be performed to prevent unexpected failures and minimize total maintenance costs (Jardine, Lin and Banjevic, 2006; Levitin, 2005; Liao, Elsayed and Chan, 2006; Inman, Farrar and Lopes, 2005). Accurate health condition prediction is critical for the effective implementation of condition based maintenance.

\section{METHODOLOGY}

This section introduces the research methodology which adopted IoT for longterm maintenance. We present the outline of methodology for the RAMS management in IoT monitoring system with failure data.

\subsection{Failure Rate Analysis of Railway Rolling Stocks}

We start from the available failure history data, FMECA: Failure Modes Effects and Criticality Analysis for improving MRUs' (Motor Reduction Units) failure. KTX (Korea Tran eXpress, Korea's high speed rail system) motor reduction unit failure data for three years include driving distant values, the number of inspected railway rolling stocks and the actual number of failed railway rolling stocks.

The MRU's FMECA data does not contain part age values and part failure distributions. Age values and failure distribution of parts can be calculated in correspondence to the actual driving distance.

The failure rates of each railway rolling stock and its parts are estimated using age values and the railway stock maintenance manual.

We chose Motor Reduction Units because MRUs are one of the most important parts related to the safety of railway rolling stocks. MRUs (Motor Reduction Units) consist of a brake cylinder, a brake shoe, and a brake disc.

\subsection{Reliability Function}

In general, railway service RAMS measures are defined by service safety and availability as measures of service effectiveness and service reliability as 
technical RAMS performance measure. The top-down methods are applied to identify and analyse the consequence scenarios of RAMS (Park, 2016).

RAMS, key performance indicators of railway rolling stock include mean time between failures (MTBF), mean time to repair (MTTR), maintenance cost, failure frequency, availability, maintainability, etc. MTBF is related to failure frequency, reliability, and availability. MTTR indicates equipment maintainability, availability, and interruption production time.

The residual lifetime of the part can be an indicator of maintenance decision making. If the usage time and the mean lifetime of parts can be measured, the residual lifetime of the part can be calculated. If the reliability function is defined as a service level, the number of parts, whose residual lifetime is greater than zero, should be greater than or equal to the service level multiplied by the total number of parts, at a given point in time.

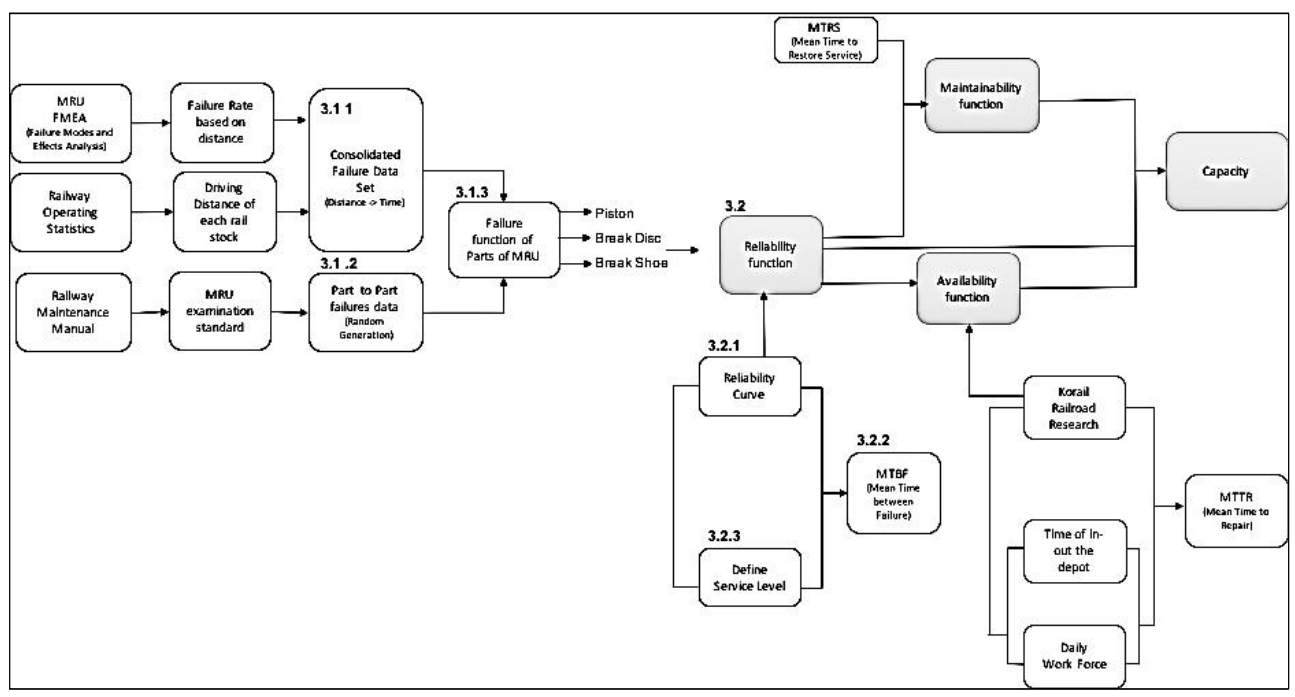

Figure 3 - Research Framework

\subsection{Condition Based Monitoring with IoT}

We characterize how RAMS methodology and failure data are tuned in section 3.1 and 3.2. We used RAMS as capacity analysis method, which is to determine the maximum number of trains that would be able to operate on a given railway infrastructure, during a specific time interval, given the operational conditions.

On this section, we will present how IoT data can be analysed for assessing railway capacity. Simulation methods and Optimization methods are one of the approaches to evaluate railway capacity (Abril, et al., 2008). We give a short description of simulation method with IoT and RAMS analysis.

Fig. 4 provides a model which determines the measures of RAMS effectiveness through the railway service level and establishes the performance of sensor 
monitoring effectiveness through the assessment of condition based monitoring maintenance. The process consists of six activities: (1) identify all possible failure modes on parts of rolling stocks. (2) the determination of the residual lifetime of parts with reliability function. (3) the determination of operational RAMS effectiveness targets (4) the assessment of maintainability performance (5) Optimization of railway capacity (6) RAMS performance verification. The sensor's data is analyzed whether it was better methodology to improve service level so that they can predict failures and reduce maintenance time.

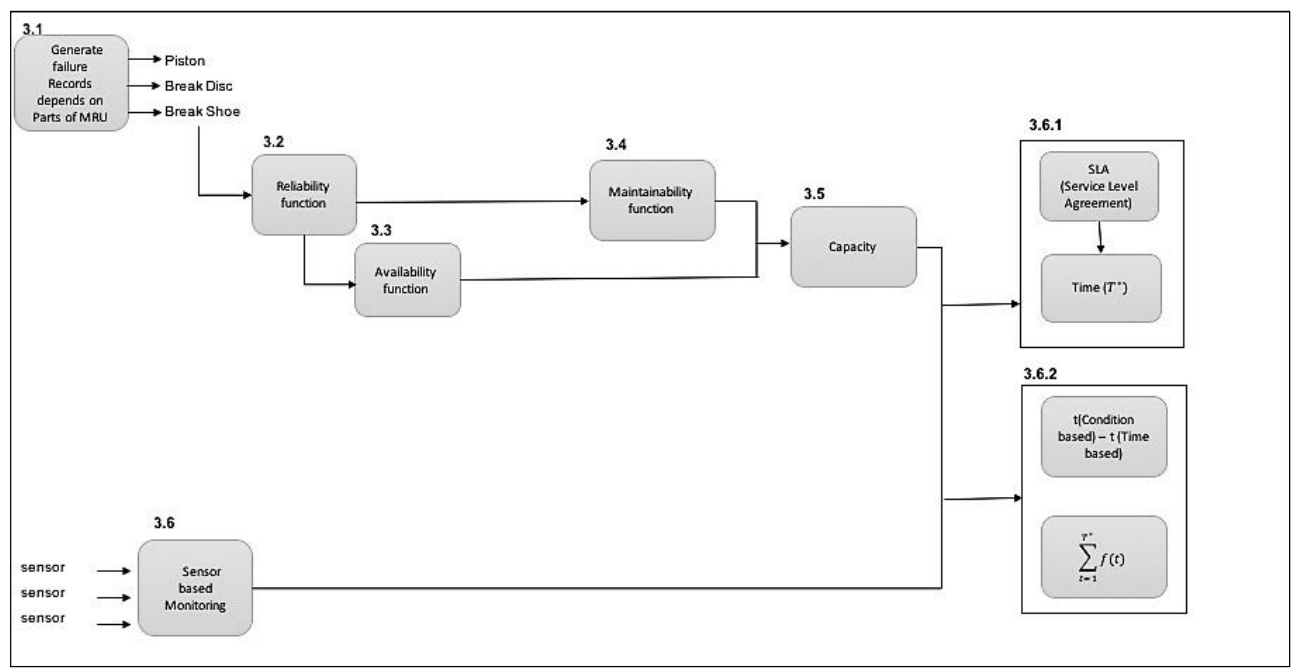

Figure 4 - Proposed CBM Monitoring Process

\section{FINDINGS}

This section provides how IoT implement on railway maintenance. It consists of two parts. First, we discuss failure rate analysis on railway maintenance. Next, we present failure prediction model that is applicable to cover reliability based maintenance and real time condition monitoring assessment.

\subsection{Failure Rate Analysis}

FMEA is useful risk assessment technique and it has been used for failure analysis of the system which can cause the failure consequences that affect railway system (Park, 2016). It is used for qualitative failure analysis of system elements, and we adapted and applied it to condition based monitoring.

As shown in Tab. 1, failure rate is increased after 1,400,000 km driving distance and radically increased after $1,800,000 \mathrm{~km}$ driving. The failure rate is a key indicator for obtaining the reliability and deciding maintenance points of railway rolling stocks. 
To compare the effectiveness of the time based maintenance with that of the condition based maintenance, we need to convert the driving distance based inspection data as to the usage time (ages of rolling stocks). In future, when we can obtain actual rolling stock MRUs condition data from IoT sensors, this conversion process will be no longer necessary. We also need to predict each MRU part's lifespan.

Table 1 - Failure Rate Analysis on Railway Rolling Stocks

\begin{tabular}{|c|c|c|c|c|}
\hline Ages (year) & Driving Distance (km) & $\begin{array}{c}\text { Number of } \\
\text { investigation }\end{array}$ & $\begin{array}{c}\text { Actual number } \\
\text { of failure }\end{array}$ & $\begin{array}{c}\text { Failure } \\
\text { Rates }\end{array}$ \\
\hline 4 & $0 \sim 600,000$ & 3 & 0 & $0 \%$ \\
\hline 8 & $600,000 \sim 1,200,000$ & 6 & 0 & $0 \%$ \\
\hline 12 & $1,200,000 \sim 1,400,000$ & 6 & 0 & $0 \%$ \\
\hline 16 & $1,400,000 \sim 1,600,000$ & 10 & 1 & $10 \%$ \\
\hline 20 & $1,600,000 \sim 1,800,000$ & 25 & 3 & $12 \%$ \\
\hline 24 & $1,800,000 \sim 2,000,000$ & 50 & 12 & $24 \%$ \\
\hline 28 & $2,000,000 \sim 2,200,000$ & 65 & 18 & $28 \%$ \\
\hline 32 & Over 2,200,000 & 20 & 9 & $45 \%$ \\
\hline
\end{tabular}

Fig. 5 offers the cumulative failure rate based on Tab. 1. The cumulative function helps to determine patterns of failure rate and to assess the extent to which each component contributes to overall failure. According to the failure prediction model, the first part failure occurs around 13 usage years.

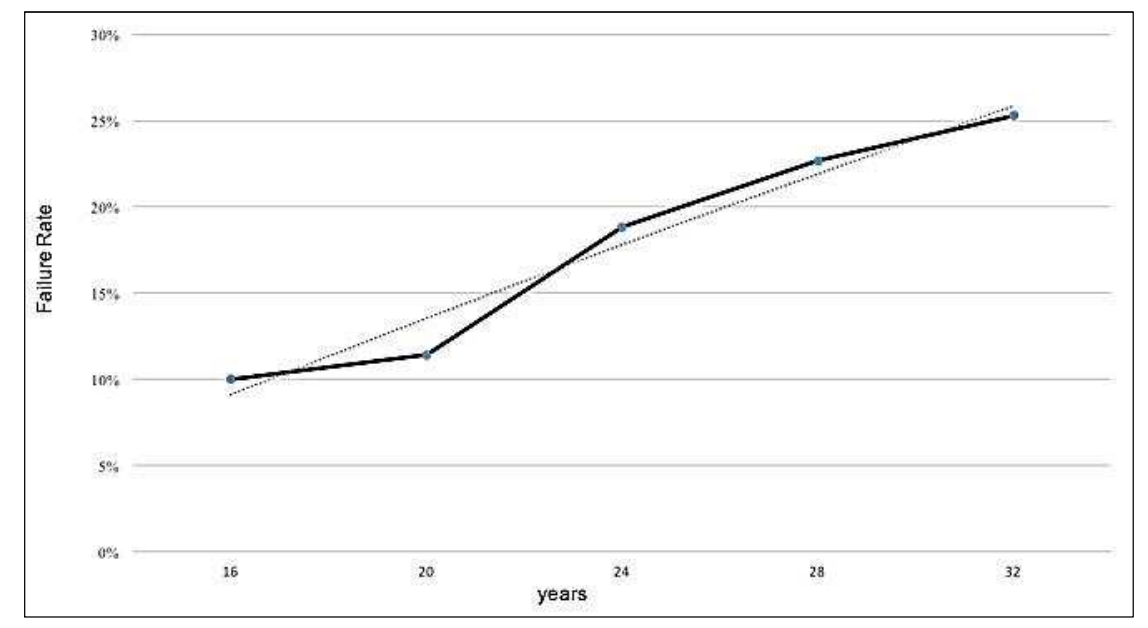

Figure 2 - The Cumulative Failure Rate

\subsection{Failure Prediction Model for MRU}

The prediction model carries out how much we can save lifespan of MRU. 
The failure rate model could be varied. As Fig. 6 shows, failure rate could be changed by maintenance strategy.

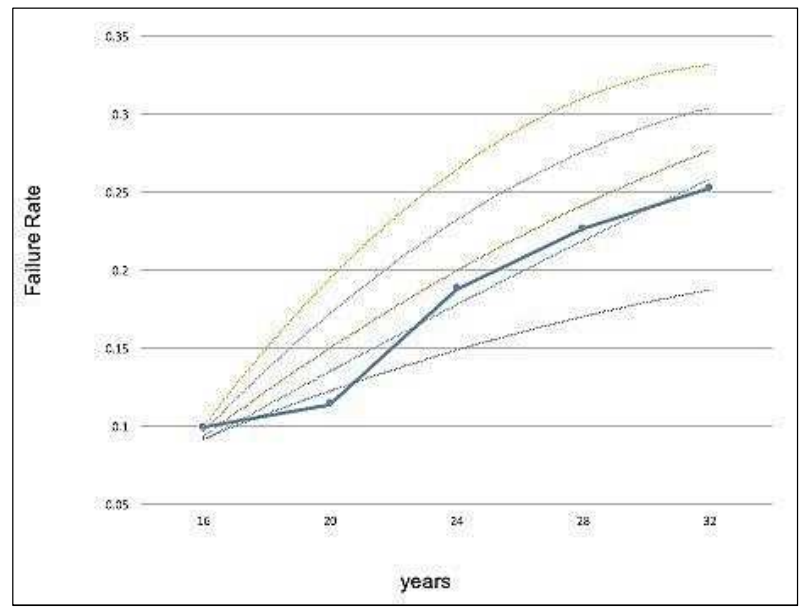

Figure 3 - Failure Rate Depending on Maintenance Performance

Another option for variation of failure rate is service level. This is possible because it defined RAMS performance level. Based on service level, RAMS performance specification is defined and it affects failure rate. The failure rate, $F(t)$, is a probability complementary to reliability, as shown below:

$$
F(t)=1-R(t)
$$

Fig. 7 shows that if the service level is increased, reliability curve moves toward left.

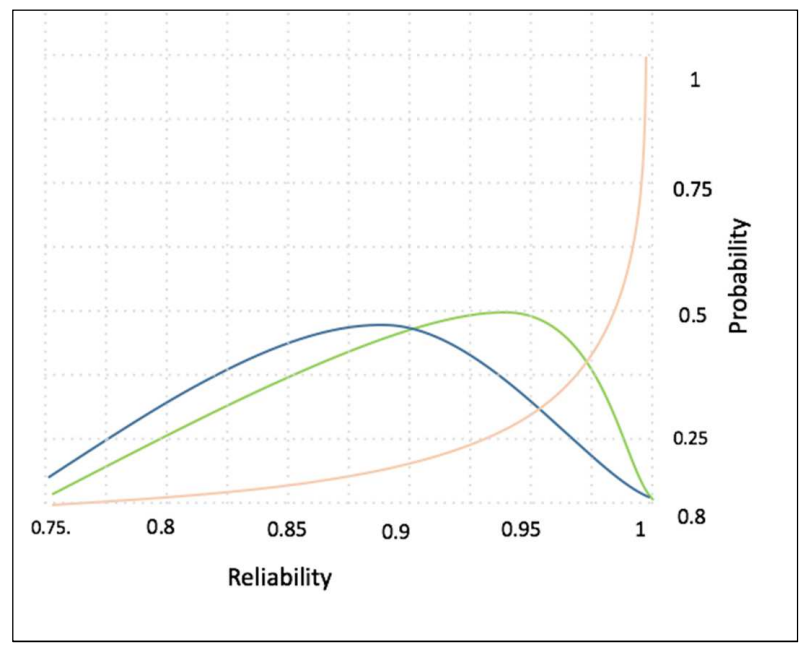

Figure 4 - Failure Probability and Reliability Probability Depends on Service Level 
Following two variations for failure prediction, we define service level in most conservative case, which is operation resource is perfectly ready. It will lead to implementing of real data set more easily.

The currently available brake cylinder failure data is not sufficiently distinctive to calculate the failure rate, but we can assume the maintenance time and part investigation period for the time being until actual IoT based sensor data are obtained.

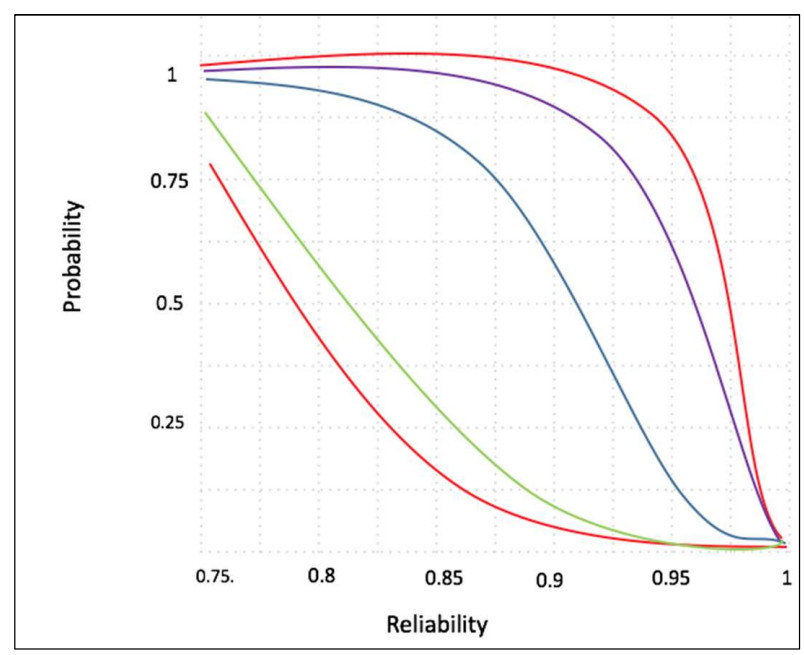

Figure 8 - Probability of Reliability Indicator for MRU Unit

\section{CONCLUSION}

Internet of Things (IoT) has been an important apparatus to improve the maintenance efficiency, but its application areas are limited to aircraft and building instruction fields. Also, its application has been concentrated on remote monitoring system only. Therefore, IoT based maintenance for rolling stock is expected to optimize maintenance content and maintenance periods while minimizing maintenance costs and prolonging the lifespan of equipment.

Furthermore, this study has the academic importance in a sense that it integrates RAMS based maintenance methods and IoT. RAMS centered maintenance provides powerful rules for deciding whether a failure management policy is technically appropriate, for providing precise criteria for deciding how often routine tasks should be carried out. It will lead to the improved cost effectiveness, sustainability, and maintainability of railway maintenance system since staff do not have to visit installation sites frequently.

Our paper presented a framework for simulation of IoT based CBM (condition based monitoring) for rolling stocks. This will helps to understand key decisions and principles to analyse the benefit of IoT. Our methodology showed that 
prediction, resolution, and gain metrics were generally useful to evaluate RAMS management on day to day operations.

However, this paper has limitations that the data are collected from references, not actual data; the detailed descriptions of IoT application to the railway rolling stocks are omitted, and how RAMS indicators are improved through the suggested reliability centered maintenance are not dealt in detail.

\section{ACKNOWLEDGMENTS}

This research was supported by a grant from R\&D Program of the Korea Railroad Research Institute, Republic of Korea.

\section{REFERENCES}

Barabadi, A., Gudmestad, O.T. and Barabady, J., 2015. RAMS data collection under Arctic conditions. Reliability Engineering and System Safety, [e-journal] 135, pp.92 - 99. http://dx.doi.org/10.1016/j.ress.2014.11.008.

Abril, M., Barber, F., Ingolotti, L., Salido, M.A., Tormos, P. and Lova, A., 2008. An Assessment of Railway Capacity. Transportation Research Part E: Logistics and Transportation Review, 44(5), pp.774-806.

Charnes, A. and Miller, M.H., 1956. A Model for the Optimal Programming of Railway Freight Train Movements. Management Science, 3(1), pp.74-92.

Duarte, J.C., Cunha, P.F. and Craveiro, J.T., 2013. Maintenance database. Procedia CIRP, 7, pp.551-556.

Hameed, Z., Vatn, J. and Heggset, J., 2011. Challenges in the reliability and maintainability data collection for offshore wind turbines. Renewable Energy, 36, pp.2154-2165.

Inman, D.J., Farrar, C.R. and Lopes, V., 2005. Damage prognosis: For aerospace, civil and mechanical systems. New York, NY: Wiley \& Sons, Inc..

Jardine, A.K.S., Lin, D.M. and Banjevic, D., 2006. A review on machinery diagnostics and prognostics implementing condition based maintenance. Mechanical Systems and Signal Processing, [e-journal] 20(7), pp.1483 - 1510. http://dx.doi.org/10.1016/j.ymssp.2005.09.012.

Kim, J.W., Park, J.-S., Lee, H.-Y. and Kim, J., 2008. A Conceptual Procedure of RAMS Centered Maintenance for Railway Systems. Journal of the Korean Society for Railway, 11(1), pp.19-25.

Levitin, G., 2005. Universal generating function in reliability analysis and optimization. London: Springer-Verlag. 
Liao, H.T., Elsayed, E.A. and Chan, L.Y., 2006. Maintenance of continuously monitored degrading systems. European Journal of Operational Research, 175(2), pp.821-835.

Park, M.G., 2016. RAMS management of railway systems. Ph. D. University of Birmingham.

Price, C.J., Pragh, D.R., Wilson, M.S. and Snooke, N., 1995. The flame system: automating electrical failure mode and effects analysis (FMEA). Proceedings of Reliability Maintenance Symposium, pp.90-95.

Scarf, P., 1997. On the application of mathematical models in maintenance. European Journal of Operational Research, 99(3), pp.493-506.

Taylor, W.A., 1998. Methods and Tools for Process Validation. [online] Taylor Enterprises, Inc. Available at: <http://variation.com/techlib/val-1.html> [Accessed 20 July 2017].

Tian, Z. 2017. An Artificial Neural Network Approach For Remaining Useful Remaining Useful Life Prediction of Equipments Subject to Condition Monitoring. N.p., n.d. Web. 28 July 2017. Available at: <http://www.csaa.org.cn/uploads/xiazai/lwj/ICRMS'2009/section_01/01-33.pdf>.

\section{ABOUT AUTHORS}

Sang Chan Park - Kyung Hee University, Republic of Korea, e-mail: sangchan@khu.ac.kr.

Yoo Jung Kim - Kyung Hee University, Republic of Korea, e-mail: yjkim191@gmail.com.

Jong Un Won - Kyung Hee University, Republic of Korea, e-mail: juwon@krri.re.kr. 